\title{
əMethods for Dispersal of Precipitated Calcium Carbonate for Stratospheric Aerosol Injection
}

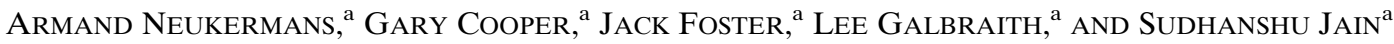 \\ ${ }^{\text {a }}$ Silver Lining, Sunnyvale, California
}

(Manuscript received 5 January 2021, in final form 28 June 2021)

\begin{abstract}
Two methods for the laboratory-scale formation of aerosols of nanosized particles of precipitated calcium carbonate (PCC), for potential use in stratospheric aerosol injection as a solar radiation management technique, are described. The first uses the coarse fluidization of bulk PCC in a simple vessel, followed by dispersal using a commercially available two-fluid nozzle. The manufacturer's measured particle mass distribution for the bulk material and sprayed aerosol particle mass distributions are compared, indicating that the sprayed particles are well separated despite a notoriously problematic agglomeration tendency. The method is suitable for scale-up. A second dispersal method, useful for small laboratory experiments, using liquid carbon dioxide as a dispersant as well as spray propellant, gave similar results. The mass mode diameters measured here $(0.89-1.4 \mu \mathrm{m})$ differ from that stated by the manufacturer $(0.7 \mu \mathrm{m})$, but the distributions are consistent in showing complete separation of the particles.
\end{abstract}

SIGNIFICANCE STATEMENT: Traditional atmospheric science studies that measure the impacts on the atmosphere of particles emitted from natural (e.g., volcanoes) and human-made (e.g., air pollution) sources are affected by the uncontrolled nature of the timing, amount, and composition of the particles. Adding small aerosols of particles of known size and composition, in a specific location and time, and measuring their evolution and interactions with other atmospheric constituents should provide better information about how aerosols affect atmospheric processes, helping to reduce a significant uncertainty that stratospheric aerosol injection could actually be implemented effectively. This strategy has not been used systematically to study processes relevant to climate change. This work provides a modest but nonetheless enabling technology for dispersing powders to create well-controlled aerosols.

KEYWORDS: Atmosphere; Stratosphere; Aerosols/particulates

\section{Introduction}

Recent analyses reveal the aggressive steps that would need to be taken to avoid significant climate warming (e.g., Rogelj et al. 2018) and associated impacts in the coming decades. There is broad agreement that mitigation of greenhouse gases is required to slow and eventually reverse climate warming; however, mitigation of carbon emissions necessary to avoid climate disruption is simply not happening in the required timeframe. Because of this, solar radiation management (SRM) and carbon dioxide removal are increasingly being investigated as potential means for avoiding the worst impacts of climate change (National Research Council 2015; National Academies of Sciences, Engineering, and Medicine 2021; Blackstock et al. 2009; Shepherd 2009). The idea behind SRM is to reduce the amount of thermal energy in the climate system by reflecting

¿ Denotes content that is immediately available upon publication as open access.

Neukermans's, Cooper's, Galbraith's, and Jain's current affiliation: Palo Alto Research Center, Inc. (PARC), Palo Alto, California.

Foster: Deceased.

Corresponding author: Armand Neukermans, armandn@ sbcglobal.net more sunlight back to space, thereby mitigating climate warming while greenhouse gas emissions reductions are implemented at the necessary scale. Among the various forms of SRM, stratospheric aerosol injection (SAI) is considered the mechanism to most reliably cool the climate, and as such has been the focus of much SRM research to date (National Academies of Sciences, Engineering, and Medicine 2021). The focus on SAI stems in part because of the observational evidence for the climatic cooling effect created by sulfur-based particles that has followed past major volcanic eruptions (Robock 2000). For SAI, both sulfate based (Crutzen 2006; Rasch et al. 2008) and nonsulfate based (Teller et al. 1997; Pope et al. 2012; Ferraro et al. 2015; Weisenstein et al. 2015; Keith and MacMartin 2015) particles have been considered as options for intentionally enhancing backscattering of incoming solar irradiance.

In its initial form, as suggested by Crutzen (2006) and others (Rasch et al. 2008), the SAI method relies on the introduction of sulfur-containing compounds like $\mathrm{SO}_{2}, \mathrm{H}_{2} \mathrm{~S}$, or $\mathrm{H}_{2} \mathrm{SO}_{4}$ into the stratosphere, where chemical processes like oxidation, hydration, salt formation, and coagulation result in the formation of suitable particles. These particles, which optimally would have a diameter of about $0.3 \mu \mathrm{m}$ (Dykema et al. 2016), would have lifetimes in the stratosphere on the order of many months if not years (Tilmes et al. 2017).

However, the introduction of large amounts of sulfur compounds (or possibly others) in the atmosphere is not without potential problems and undesirable side effects (Crutzen 2006; Kravitz et al. 2014; Weisenstein et al. 2015; National Research Council 2015). A leading issue is that these sulfur compounds 
can interact with chlorine in the stratosphere (e.g., from CFCs) to deplete stratospheric ozone concentrations (Robrecht et al. 2021). For example, in order to obtain a radiative forcing of $-2 \mathrm{~W} \mathrm{~m}^{-2}$ using sulfur-based particles in SAI, these compounds might reduce the ozone concentration in the stratosphere by a modest but not insignificant 1\%-13\% (Keith et al. 2016).

The search for an efficient scattering agent without significant unwanted properties is still ongoing. A point in sulfur's favor is that in principle only atomic sulfur itself needs to be brought up while the subsequent oxidation can occur in the stratosphere with chemical compounds already present, without further intervention. This of course significantly reduces the mass that needs to be uplifted and thus the cost of the operation (Smith et al. 2018). Initial quantities are estimated to be on the order of 1-2 million metric tons per year (Rasch et al. 2008), gradually expanding over time (Teller et al. 1997; Blackstock et al. 2009; Pope et al. 2012). More recent calculations suggest a total of 24 million metric tons (as $\left.\mathrm{SO}_{2}\right)$ over the first 15 years of deployment (Smith and Wagner 2018).

Desirable requirements of these particles are high real, and minimal imaginary, parts of the refractive index for efficient backscattering and low IR absorbance, an optimum particle size (on the order of $0.2-0.3 \mu \mathrm{m}$ ) for a long dwell time, low cost, chemical stability, and minimal toxicity (Dykema et al. 2016; Weisenstein et al. 2015).

A promising particle candidate is calcium carbonate (calcite; Keith et al. 2016). For an injection rate of $2.1 \mathrm{Mt} \mathrm{yr}^{-1}$, a radiative forcing of $-1 \mathrm{~W} \mathrm{~m}^{-2}$ might be achieved. Based on the removal of hydrogen halides and nitric and sulfuric acids from the stratosphere by the formation of stable solid salts with the carbonate, it was originally thought that this might result in the enhancement of the atmospheric ozone concentration by $3.8 \%$ (Keith et al. 2016). However, more recent laboratory experimental work suggests that particle aging effects might actually result in a reduction of the global mean ozone column of up to 3\% (Dai et al. 2020). Thus, more research is clearly needed on the potential effects of calcium carbonate but is beyond the scope of this paper.

Calcium carbonate (Carr and Frederick 2000) is present in abundance on Earth and is mined worldwide in the form of limestone or dolomite at the rate of about 15 billion metric tons per year, which is more than 2 times that of mined coal. Key uses are in in the healthcare, oil, plastic, rubber, cement, glass, paper, construction, and steel industries. Calcium carbonate powders are prepared by two different methods-attrition and precipitation. The precipitated form is available in several crystal habits and sizes and has a much finer particle size distribution, for which reason it is of most interest in this case. Calcium carbonate is generally considered nontoxic. The precipitated form is occasionally observed as a natural phenomenon in the Caribbean when the ocean is seen to turn milky white during the hotter parts of the day. As the surface temperature rises and the water becomes supersaturated, calcium carbonate precipitates, redissolving during the cooler night.

In contrast to sulfur compounds, forming calcium carbonate particles in situ in the upper atmosphere at scale looks extremely difficult at best, due to complex chemistry and physical processing issues. Hence should SRM techniques ever need to be applied, the most cost-effective deployment would probably necessitate large-scale production in industrial installations at ground level and subsequent transport to the stratosphere. An additional issue is the extensive agglomeration of these particles in dry powder form. The successful dispersal of these or other submicrometer particles as a suitable aerosol with the right particle size distribution at scale does not look like a foregone conclusion, even if the dry powder distribution is deemed suitable. At scale would mean initial quantities on the order of 1 million $\mathrm{Mt} \mathrm{yr}^{-1}$. Few if any aerosol dispersal methods described in the literature offer the potential for dispersing a million $\mathrm{Mt} \mathrm{yr}^{-1}$ [Prenni et al. (2000) presents an interesting possibility]. A review of methods of generating solid aerosols (Silverman and Billings 1956) describes many techniques and lists many pulverized materials that have been aerosolized by resuspension, including some that are submicrometer in size. Instruments that provide reliable particle sizing of submicrometer aerosols did not exist in 1956. The present experiments were undertaken as a small feasibility project to find useful methods for aerosol dispersion and, using modern instrumentation, verify that the resulting particle size distribution is congruent with that of the bulk material. To quote Keith et al. (2016), "The most obvious engineering unknown would seem to be the ability to dispense solid particles while avoiding agglomeration."

\section{Characterization of the bulk source material}

The material used in most of these experiments came from a sample of Albafil T10, supplied by Specialty Minerals, Inc. A scanning electron microscope (SEM) image of the powder, along with the cumulative mass and particle size distributions as determined by the manufacturer, are seen in Fig. 1.

These measurements were made using the SediGraph method, where the absorption of an X-ray beam is measured as a function of the sedimentation of the particles in a fluid, from which the mass fraction of the particles can be extracted based on mass absorption. From the cumulative mass distribution, the particle mass distribution is readily determined by differentiation.

However, it is difficult to determine with great precision the exact particle size distribution from the mass distribution, because of the steep dependency of particle mass on diameter. A large number of particles of low mass barely register in the mass distribution. This is illustrated Fig. 2, which shows the cumulative mass distribution as supplied by Specialty Minerals and two functional fits to that distribution. One fit is a lognormal distribution and the other based on a hyperbolic tangent function. Both functions give a good fit, with the tanh function assessed to be a better approximation to the (estimated) lower end of the distribution.

It is seen in Fig. $3 b$ that the derived particle mass distributions from these analytical representations are very similar (peaking at 0.63 and $0.65 \mu \mathrm{m}$ vs the manufacturer's nominal $0.7 \mu \mathrm{m}$ ), but the resulting particle number distributions are vastly dissimilar and diverge completely in the smaller diameter region of interest. The lognormal simulation gives a number distribution peak at $0.3 \mu \mathrm{m}$, while the tanh simulation gives rise to a continuously rising number distribution. This is 
a)

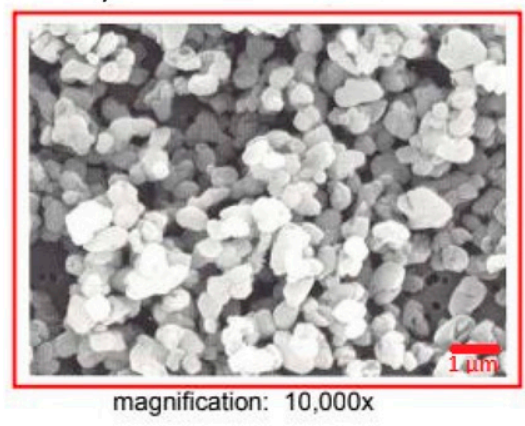

b) Cumulative Particle Size Distribution Total \% weight below each micron size

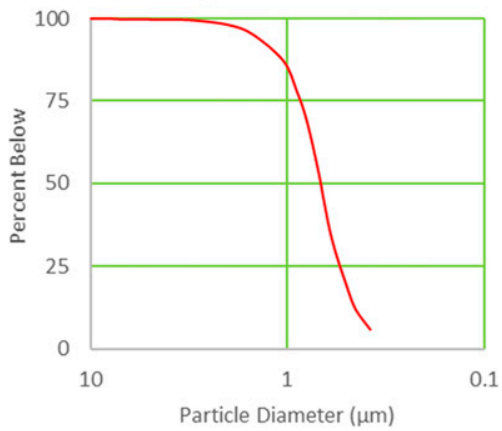

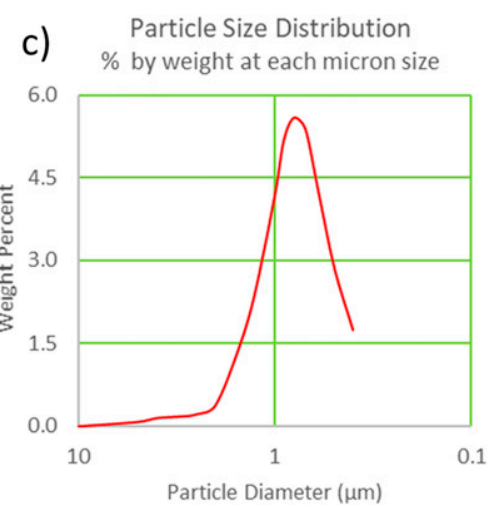

FIG. 1. (a) SEM photograph showing agglomeration of particles, and plots of (b) cumulative mass and (c) particle mass distribution of Albafil T10, determined by SediGraph, per the supplier. The nominal particle mass diameter as measured by the supplier is $0.7 \mu \mathrm{m}$.

of course a direct result of the steep $1 / d^{3}$ diameter dependence of the number distribution curve. Thus, the real particle distribution might be either peaked or continuously rising, or perhaps somewhere in between.

To attempt to resolve this problem, we had a sample analyzed on a state-of-the-art flow cytometer, courtesy of Beckman Coulter Life Sciences. In brief, a flow cytometer is a laser scattering instrument (often using multiple wavelengths) that is predominantly used to simultaneously measure the size, shape, fluorescence characteristics, and other properties of living (or diseased) cells. Here, in contrast to standard laser scattering instruments the particles are carefully positioned in a micrometer-sized thin liquid sample stream, itself carefully positioned in the center of a sheath flow. Thus, particles are surrounded by water rather than air, and the focused laser beam diameter is usually a few micrometers rather than hundreds of micrometers, giving very good sensitivity. The arrangement of the sheath flow cell is also designed to enhance separation of particles, so agglomeration is minimized. While the conceptual operation is very similar, Mie scattering (which assumes a plane wave) is not strictly applicable, although the differences should be minor.

A measurement result is illustrated in Fig. 4. The continuous gray distribution is the result of calcium carbonate particle scattering, while the colored stripes are polystyrene latex (PSL) calibration spheres, added as size references.

Here, the horizontal axis represents the intensity of the electrical output signal, and the vertical axis represents the counts in the various size bins. The polystyrene spheres have different fluorescent tags and therefore can be readily distinguished from the calcium carbonate particles. These spheres, after application of a Rayleigh scattering correction factor, allow for the reconstruction of a histogram of the particle size distribution.

The refractive index of the medium (water) is 1.33 at the wavelength of illumination, the polystyrene spheres have an index of 1.615, and the calcite crystals, which are birefringent, have indices of 1.68 and 1.496 for the ordinary and extraordinary rays, respectively. Averaging the appropriate index expressions for those two rays, and comparing this with the polystyrene sphere, we find that for an identical size, the polystyrene spheres in water scatter more by a factor of 1.12, and thus, their intensities need to be reduced by this factor, when projected on the calcium carbonate light distribution (Kondo et al. 2013).

To get to a real size distribution this graph also needs to be rescaled. The count represents the data collected in geometrically scaled intensity bin widths (i.e., 256 bins between $10^{3}$ and $10^{7}$ ). First the resulting horizontal axis (light intensity) is rescaled into a carbonate diameter with the aid of the PSL spheres (after, as stated, normalizing all indices to water, and accounting for the two values of the index of refraction of calcium carbonate). The resulting diameter bins are however unequal in width, and a real distribution is only obtained after the count (i.e., the vertical axis) is normalized to the diameter

\section{Simulated Cumulative Mass Distribution for Albafil ${ }^{\circledR}$ T10}

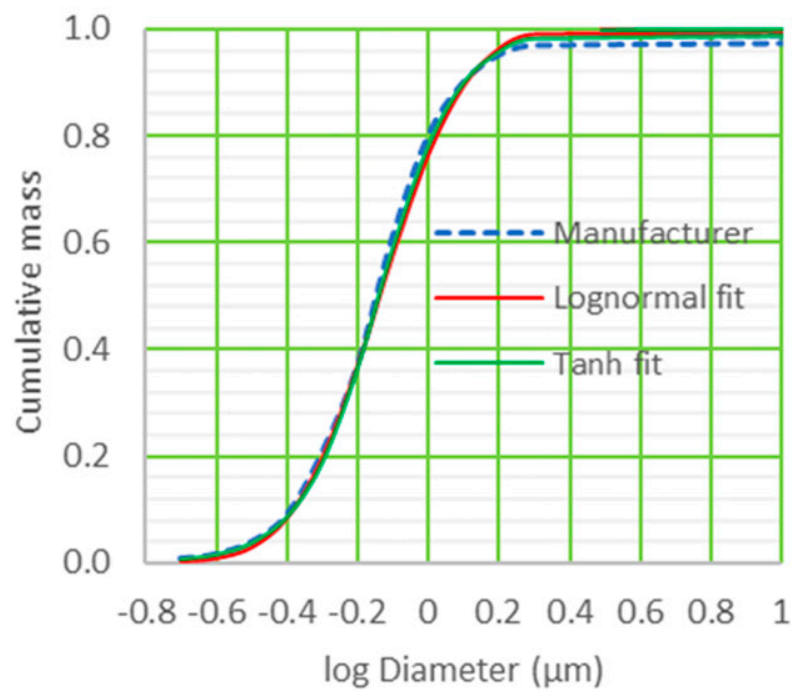

FIG. 2. Manufacturer's experimental data and simulations of the cumulative mass distribution of Albafil T10, showing good fit to lognormal and tanh simulations. 

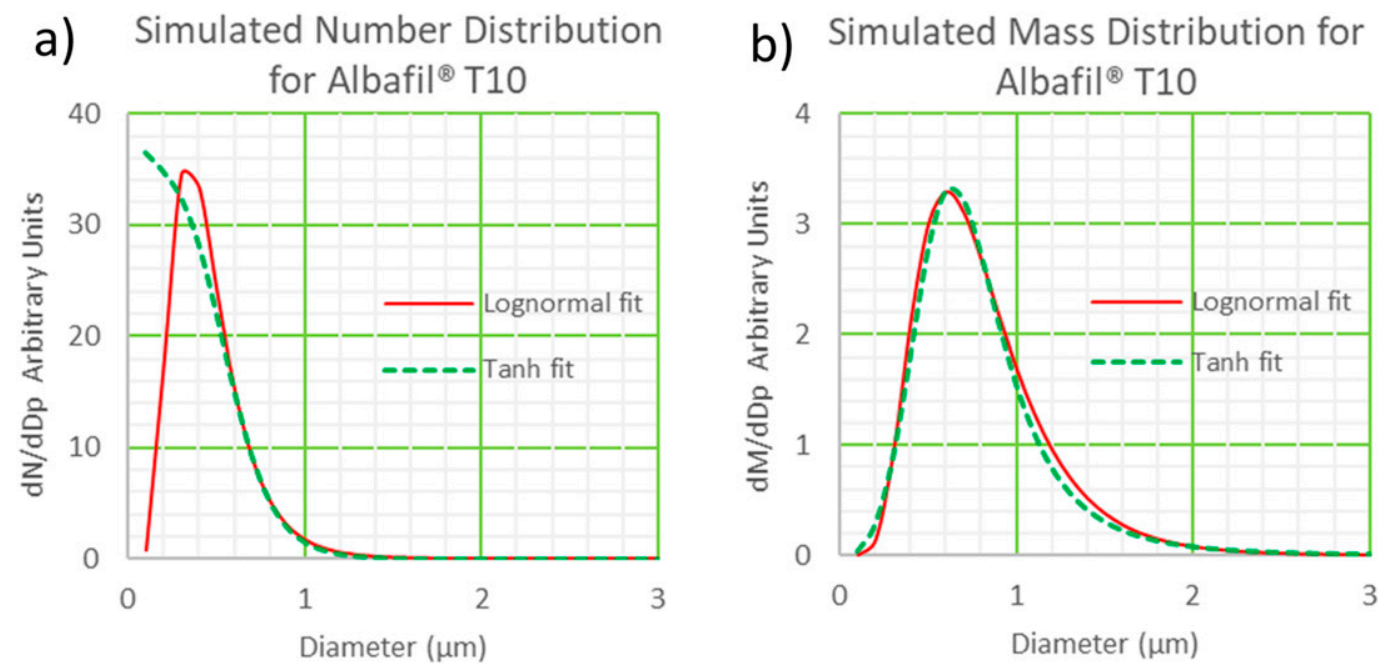

FIG. 3. The (a) number distribution and (b) mass distribution resulting from the cumulative mass distribution simulations of Fig. 2.

bin widths. The resulting number and mass distributions are illustrated in Fig. 5.

As seen in Fig. 5, there is no distinct peak in the number distribution but a rapidly rising number at small diameters. The peak of the particle mass distribution is found to be at $1.4 \mu \mathrm{m}$ rather than $0.7 \mu \mathrm{m}$ as specified by the manufacturer. The measurement was repeated with a strongly ultrasonically agitated sample, just to make sure that all particles were well separated, but the results were identical. As will be seen, these results are corroborated by additional measurements of the airborne aerosol particles. Since the particle mass distribution gives more useful information than the number distribution it will be used from hereon when displaying distribution data from other measurements.

\section{Fluidization and spraying of ALBAFIL T10 precipitated calcium carbonate}

Fluidization is the process whereby a quantity of particulates is converted into a quasi-fluid-like state by having a fluid of different density (often air) flowing through it. It turns out that true fluidization of submicrometer calcium carbonate (as for most micrometer-sized particles) is exceedingly difficult, as explained by Geldart (1973).

The criteria for fluidization outlined by Geldart (1973) are based on particle size and the density difference between the fluidizing medium and the particles. Four classes of particles (A-D) are defined in the diameter-density difference phase space. Particles in group A are easily fluidized, particles in group B with moderate effort, those in group D would require enormous gas flows and hence lead to economically undesirable processes, and for those in group $\mathrm{C}$, fluidization is extremely difficult to achieve. Albafil T10 is solidly in group C, and the manufacturer's datasheet points out that it is exceedingly difficult to disperse even in powder form, requiring very high shear. These cohesive carbonate particles also show strong adhesion to many materials, including polytetrafluoroethylene (PTFE).

Thus, while proper fluidization of single particles cannot be achieved, it seems conceivably possible to create and fluidize coarse particle agglomerations, which then might be fed to a nozzle for further separation.

The best results were obtained with a homemade device illustrated in Fig. 6a. The $6.35-\mathrm{cm}$ (inside diameter) by $10.2-\mathrm{cm}$ (height) acrylic particle chamber has a porous bottom, and a flow of air is fed in at the bottom through an overlain porous support layer (steel wool) that is in turn covered with a tautly stretched porous membrane, to diffuse the airflow uniformly across the bottom surface. We tried several commercial Millipore filters but found that standard paper coffee filters were best overall for mechanical strength. In addition, stirring or some mechanical agitation is usually of some help to get a

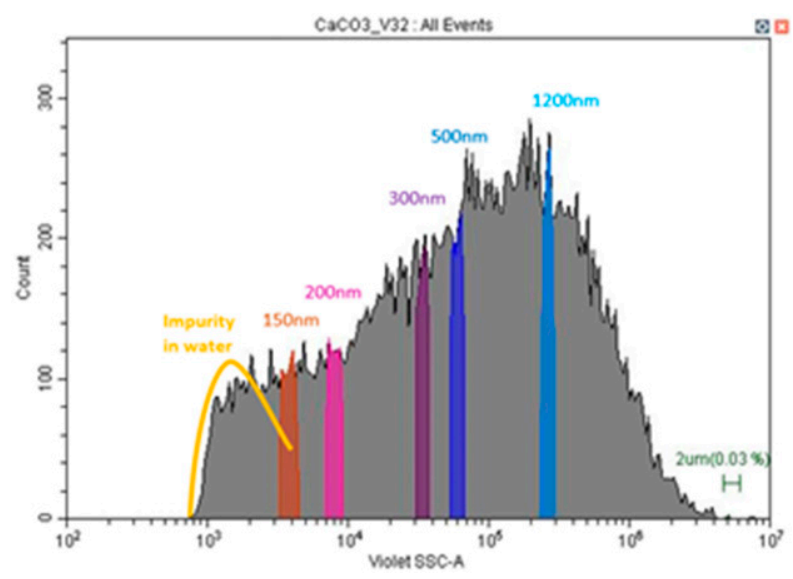

FIG. 4. Albafil T10 flow cytometer scattering measurements, with PSL spheres for calibration. Horizontal axis: light intensity (A/D electrical signal); vertical axis: counts per second. 
a) Flow Cytometric Number Distribution

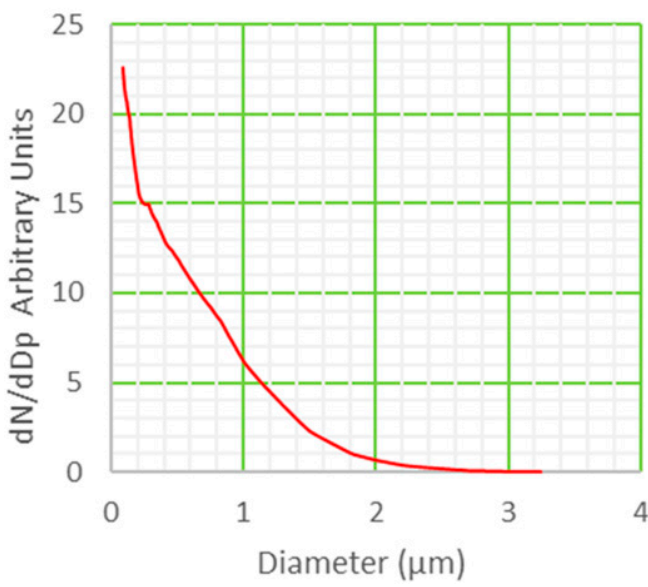

b) Flow Cytometric Mass Distribution

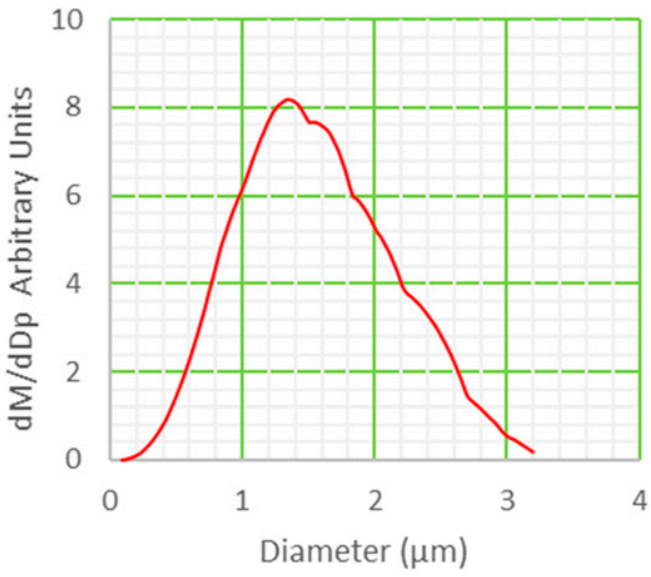

FIG. 5. The (a) particle number distribution and (b) mass distribution for ALBAFIL T10 as determined by flow cytometry, showing a mass mode diameter of about $1.4 \mu \mathrm{m}$.

continuous upwelling of powder. Several commercial magnetic stirrers, designed for stirring liquids, were found inadequate for the job. We designed a rotor outfitted with neodymium magnets and a stirrer bar consisting of a longitudinally magnetized 0.25 -in.-diameter $(6.35 \mathrm{~mm})$ neodymium magnet to create a strong magnetic circuit, which managed to stir the powder under nearly all circumstances (although not always gracefully). Even under optimum conditions of this configuration, the arrangement does not fluidize individual carbonate particles, but mostly agglomerations of particles, estimated to be tens of micrometers in diameter. However, this agglomerate behaves somewhat as a fluid and is suitable for pressure feeding or aspiration into a nozzle.

\section{a. Nozzle selection}

The function of the nozzle is to achieve decomposition of the agglomerates into separate particles, using the energy in the turbulent flow of an added high-velocity gas stream. It was thought that a two-fluid effervescent nozzle using choked flow (Cooper et al. 2014), developed for marine cloud brightening (MCB; another proposed SRM technique), might be useful for this purpose, with fluidized calcium carbonate particles replacing the liquid phase. While the scheme might be made to work, in practice clogging took place almost instantly. The diameter of the "fluidized" carbonate particle agglomerates cannot be accommodated by the orifice dimensions of our existing nozzles (200-300 $\mu \mathrm{m})$.

A commercial Schlick model 970 form 5 nozzle, a research grade adjustable two-fluid nozzle with a larger orifice, was also tried, but again clogging took place almost immediately. It became apparent that much larger orifices would be needed.

Following a communication from the Harvard group, reporting some interesting work by technicians at the Schlick factory with a larger and more compact version of this nozzle, a model
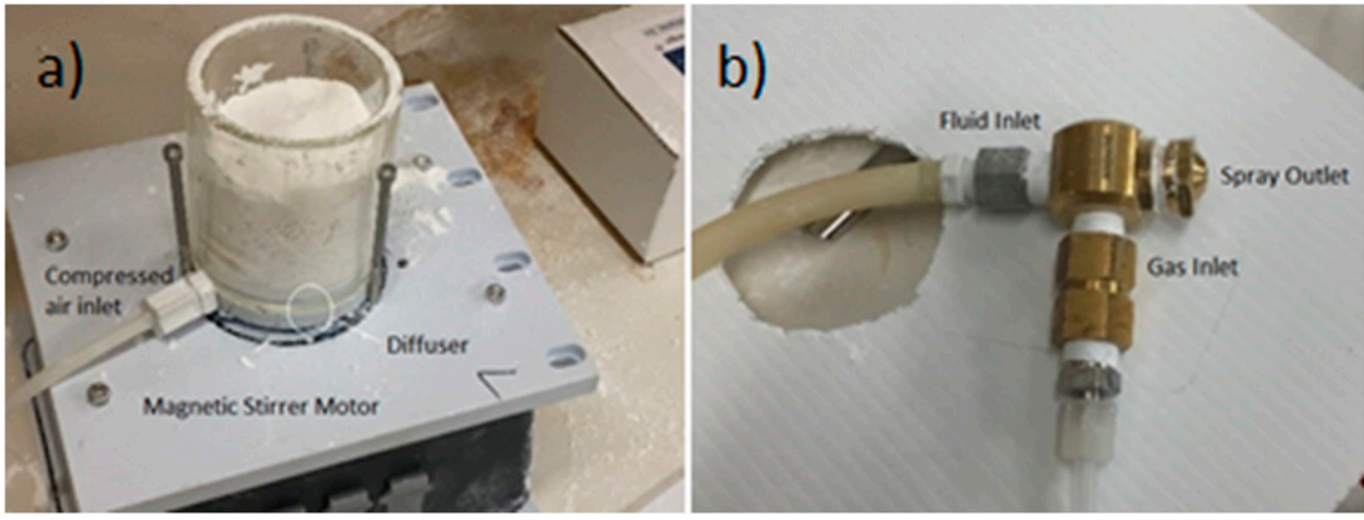

FIG. 6. Pictures of (a) the magnetically stirred fluidization chamber and (b) the Schlick 940 form 6 nozzle used to fluidize and then spray Albafil T10. The large flexible rubber tube attached to the fluid inlet of the nozzle is $0.5 \mathrm{in}$. $(12.7 \mathrm{~mm})$ in diameter and is dipped in the fluidized carbonate during operation to aspirate fluidized particles. 

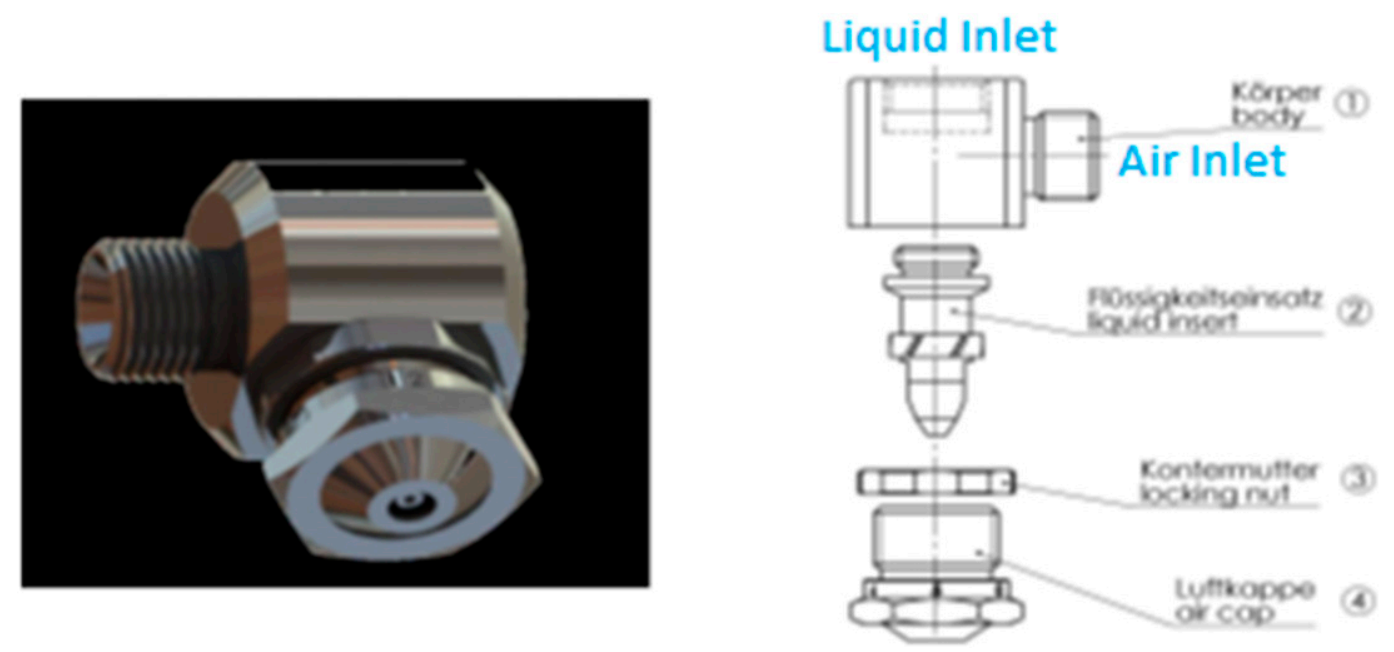

FIG. 7. The Schlick model 940 form 6 two-fluid nozzle used for spraying crudely fluidized Albafil T10: (left) photograph and (right) detail drawing. The fluidized material enters via the liquid inlet, passes through the center of the liquid insert, and exits through the smaller of the apertures seen in the photograph. Compressed air enters via the air inlet, swirls around the outside of the liquid insert, and exits through the larger of the apertures.

940-form 6 (Fig. 7 and Fig. 6b) was tested. This not an effervescent model, as there is no chamber for mixing the two fluids.

As can be seen from the outlay drawing, the "liquid," that is, in our case the fluidized powder, is brought in at the center. The supply air is brought in from the side and is given a swirling motion by the slanted grooves on the liquid insert before exiting around the inner fluid orifice. The exit flow restriction provides a significant negative pressure (by the Bernoulli principle), right at the exit of the center tube, enough to suck in the fluidized powder and disperse it into the air. The arrangement of locking nut and air cap is experimentally adjusted to obtain maximum negative pressure.

This nozzle has a 2-mm aperture, requiring substantially more air, but it does not clog, at least for a considerable period of time. Although the nozzle does stay operational, after a few seconds of continuous operation in its present form, some powder builds up on the inside where there are abrupt transitions in diameter of the nozzle changing the effective orifice.

For optimal operation, it would be highly desirable to make a nozzle where all diameter transitions in the powder trajectory are as gradual as possible, to avoid stagnation points and hence accumulation sites for particulates. The nozzle also should preferably be constructed of material to which the carbonate particles exhibit low adhesion (stainless steel, possibly glass) or low triboelectric effects. Alternatively, as will be described, with a pulsed system, the nozzle can be periodically cleaned at the end of each powder puff.

Operation of the nozzle in a fume hood, even for a few seconds, appeared to overload the fume hood and all our measurement instruments for a considerable amount of time and was found to be impractical. Therefore, the aerosol was dispersed in a laboratory room about $155 \mathrm{~m}^{3}$ in volume, stirred by two fans.

The inlet pressure and the actual airflow to the nozzle were observed to decrease over time, not surprisingly given the high flow rate and long supply lines (even with buffer reservoirs) of our laboratory setup. For this reason, we decided to operate the device in pulsed mode. A KIP model 141111 solenoid valve in the air supply line was opened for $0.2 \mathrm{~s}$ at 1 -s intervals. This provides a much better controlled form of operation without clogging. With an additional simple modification to the configuration, it would be possible to send a cleaning blast of air through the central feedline of the nozzle, thereby avoiding clogging of the nozzle over extended periods of time. This was not implemented, as our experiments required only a few blasts to provide enough aerosol to overwhelm our analytical instruments.

The nozzle was operated at $40 \mathrm{psig}(1 \mathrm{psig}=0.07$ bar $)$ air pressure minimum. Given the adequate results obtained, a lower value might be used to reduce air consumption (at 10 psig the airflow would drop by a factor of 2.5). At 40 psig, the total flow exiting the nozzle was about $150 \mathrm{~L} \mathrm{~min}^{-1}$, with $25 \mathrm{~L} \mathrm{~min}^{-1}$ aspirated through the suction tube and hence some $125 \mathrm{~L} \mathrm{~min}^{-1}$ coming from the air supply.

To measure the amount of dispersed carbonate, we sprayed into a tared plastic bag, with a volume calculated to be $21.5 \mathrm{~L}$. It took about $9 \mathrm{~s}$ to fill the bag in continuous mode, and some 50 pulses in pulse mode (i.e., $50 \mathrm{~s}$ ). In either case, we found that the weight increase due to the particles was $4 \mathrm{~g}$. Thus, the mass delivery rate is $0.4 \mathrm{~g} \mathrm{~s}^{-1}$ in continuous mode and is smaller by approximately a factor of 5 in pulsed mode, as would be expected. The air in the bag has a calculated mass of $25.3 \mathrm{~g}$, so the mass ratio of air to carbonate is $25.3 / 4=6.3$. It is a telling story that the plastic bag we used had a few tiny pinholes, and, when inflated with aerosol, beautiful, tiny, wispy plumes emerged from these holes, eerily reminiscent of cigarette smoke, which happens to comprise particles with diameters between 100 and $400 \mathrm{~nm}$.

The mass flow of carbonate could be reduced by decreasing the pulse rate or the pulse duration. Likewise, if desired, the 
a) POPS and Flow Cytometry Mass Distributions

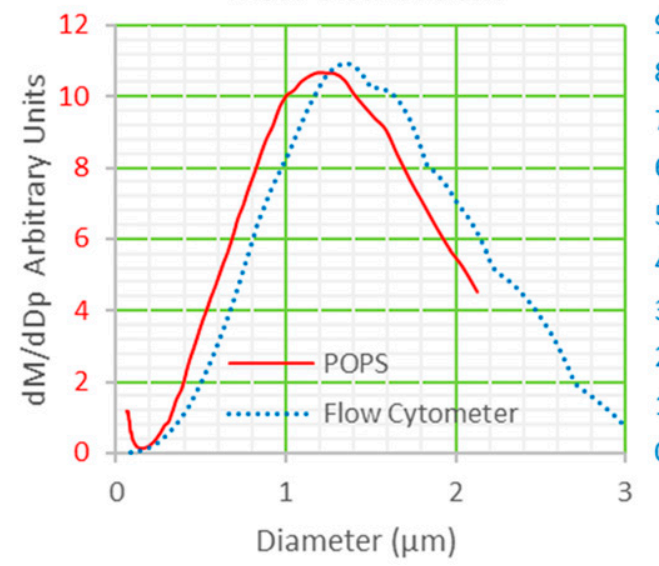

b)

9
8
7
6
5
4
3
2
1
0

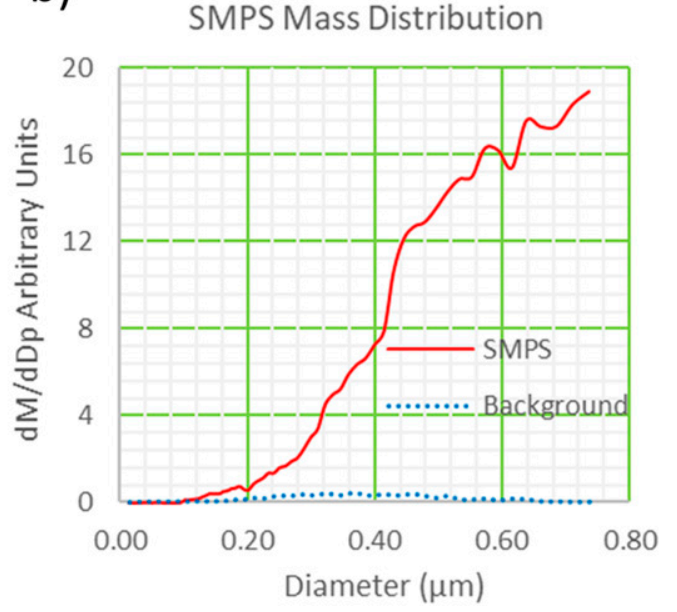

FIG. 8. The particle mass distribution of Albafil T10 aerosol produced using the fluidization chamber and spray nozzle shown in Fig. 6, as determined by (a) POPS, showing a mass mode diameter of $1.2 \mu \mathrm{m}$, with a scaled overlay of the particle mass distribution of the bulk (unsprayed) material as determined by flow cytometry; and (b) SMPS, showing no evidence of a submicrometer mass peak.

mass flow could probably be significantly enhanced by increasing the pressure in the fluidization chamber. The chamber of Fig. 6a can be covered with a lid, thereby providing a positive pressure arising from the air used to fluidize the particle bed. That overpressure easily exceeds the negative pressure created by the venturi effect and enhances the particle delivery significantly. Although this arrangement seemed to work, no quantitative experiments were performed using this method.

\section{b. Measurement of the sprayed carbonate aerosol particle distribution}

We had at our disposal at this point two particle size measurement instruments: a NOAA Printed Optical Particle Spectrometer (POPS; Gao et al. 2016) — a laser scattering instrument on loan from Harvard-and a TSI model 3080 Scanning Mobility Particle Sizer (SMPS) that was equipped with a TSI model 3081 Differential Mobility Analyzer (DMA) and a TSI model 3010 Condensation Particle Counter (CPC). As configured, the SMPS covers a particle size range of 0.014 $0.735 \mu \mathrm{m}$, whereas the POPS covers a range of $0.14-3 \mu \mathrm{m}$. There was an initial concern that the latter range might not be wide enough to see large particle agglomerations, but in retrospect as will be seen, this measurement range was adequate.

The POPS publication (Gao et al. 2016) provides significant data on its response to PSL spheres, which can in principle also be used to calibrate the instrument for $\mathrm{CaCO}_{3}$ particles. Given the importance of the POPS as a possible lightweight, rugged, and ultracompact monitoring instrument for carbonate measurement in the field, it was decided to calibrate the POPS directly with carbonate particles, using the SMPS as a particle size filter. A detailed description is given in appendix A.

Experiments were conducted using the SMPS, the POPS, and a Climet particle counter (model CI-150t-01), with inlets in close proximity. The Climet (with 100/1 input dilution) has poor size discrimination but was added as it is useful in detecting overload conditions. As for all optical scattering instruments, the POPS is extremely sensitive to particle overload from dense aerosols, which can give rise to an erroneous enhancement of the number of large particles.

Figure 8 a shows a typical particle mass distribution for an aerosol created by spraying Albafil T10 at 80-psig nozzle pressure, using the fluidization chamber and nozzle shown in Fig. 6a, with a scaled overlay of the particle mass distribution of the bulk material obtained by flow cytometry (Fig. 5). The shapes of the curves are in good agreement, and the mass mode diameters differ by $0.2 \mu \mathrm{m}$ ( $1.2 \mu \mathrm{m}$ by POPS and $1.4 \mu \mathrm{m}$ by flow cytometry).

The SMPS is probably the most reliable instrument of all those at our disposal, although its measurement range is limited to $0.014-0.736 \mu \mathrm{m}$. Data from an SMPS scan run at the same time as the POPS data shown in Fig. 8a were collected are presented in Fig. 8 b, along with a background scan before spraying.

Because of the lack of information from even larger diameter particles, the SMPS cannot correct for multiply charged particles in the larger diameter half of the distribution as its "multiple charge correction" function is programmed to do. This can be seen in the large increase around $0.43 \mu \mathrm{m}$. Hence the particle mass data beyond $0.43 \mu \mathrm{m}$ are probably overestimated by $30 \%$ or more.

As can be seen from Fig. 8b, the mass distribution increases substantially over its measurement range, in some fashion that is similar to the POPS instrument as seen in Fig. 8a. Also, in agreement with the flow cytometry and POPS measurements of the bulk material, there is no peak in $d M / d D_{p}$ around $0.7 \mu \mathrm{m}$, as suggested by the manufacturer's datasheet.

What is clear from all of the above data is that the carbonate particles are very well dispersed using a simple setup.

\section{Particle dispersal using liquid $\mathrm{CO}_{2}$}

For small amounts of carbonate dispersal, a much simpler method consists of spraying a powder suspension in a suitable 


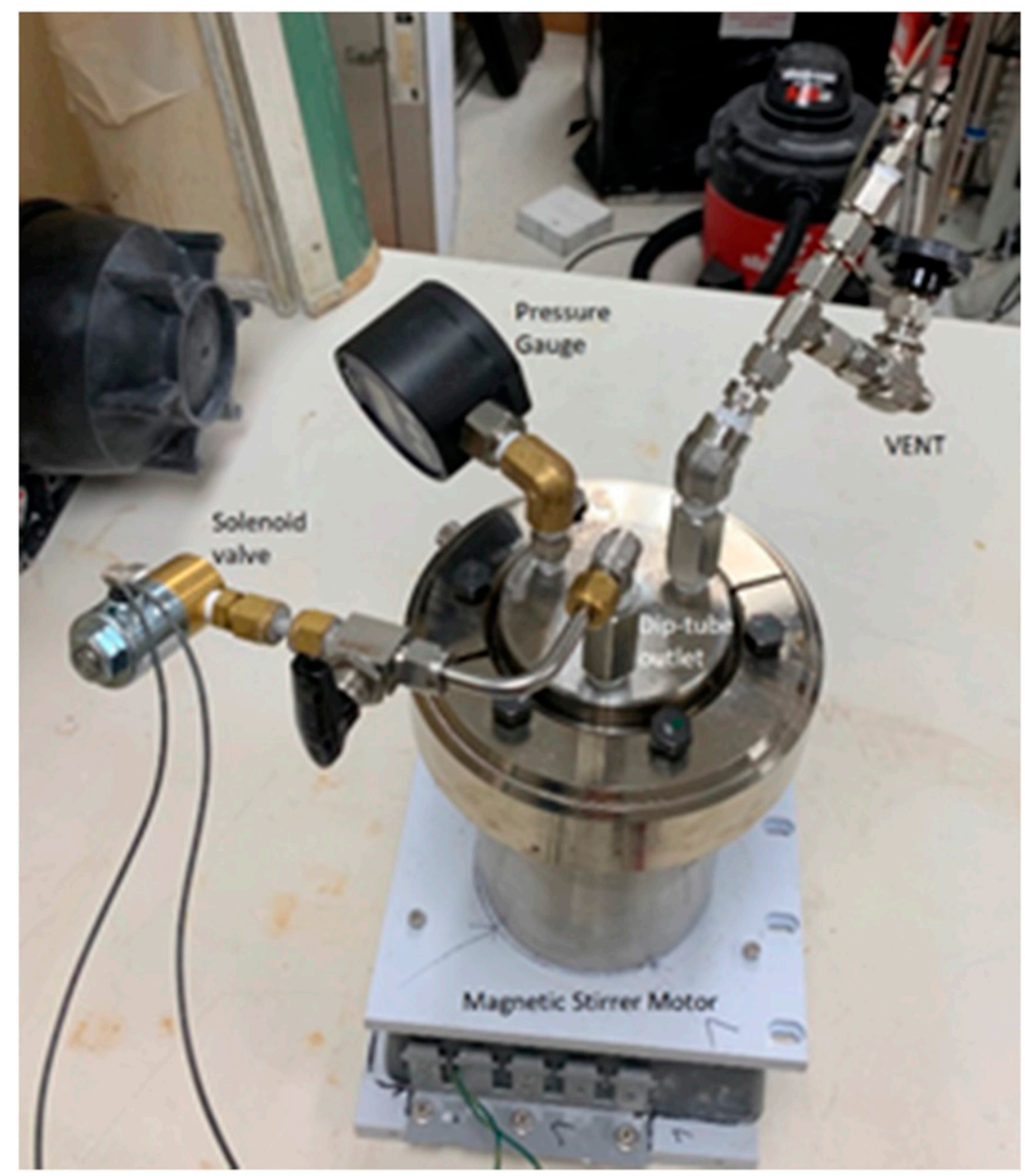

FIG. 9. The 1-L Parr pressure vessel and valves used for spraying liquid $\mathrm{CO}_{2}$ suspensions of Albafil T10. The connection at " 2 o'clock" orientation provides a vent but is otherwise sealed off. The dip tube at " 6 o'clock" orientation feeds the suspension through a high-pressure on-off valve to a solenoid valve in this photograph but directly to a nozzle in other cases (not shown).

carrier liquid. Although various liquids might be used, perhaps somewhat ironically, liquid $\mathrm{CO}_{2}$ appears to be the preferred choice to disperse calcium carbonate, particularly for exploratory experiments in the stratosphere. The process consists of adding a known mass of powder to a given mass of dry solid $\mathrm{CO}_{2}$ in a stainless-steel pressure vessel, together with a magnetic stirring bar. The vessel is then sealed, and as the $\mathrm{CO}_{2}$ evaporates, a liquid is obtained with a given mass fraction of suspended particles. The particles are kept in suspension by stirring.

Dispersion results that are similar to those of the fluidization/spraying method discussed above were obtained, but some small effects, presumed to be a result of the cooling associated with the use of liquid $\mathrm{CO}_{2}$ were observed. All experiments were performed with a Parr Instruments stainlesssteel pressure vessel (Series 4600, Fig. 9). The vessel was loaded with $60 \mathrm{~g}$ of Albafil T10 and $240 \mathrm{~g}$ of dry ice, resulting in a $20 \%$ by weight carbonate suspension. That percentage was chosen since aqueous suspensions of similar weight loading seemed very suitable for spraying and water has almost the same density as liquid $\mathrm{CO}_{2}$. The flat bottom of the vessel was supported above a motor that carries a homemade magnetic stirrer. A 2-in.-long $(50.8 \mathrm{~mm})$ magnetic stirring bar inside of the vessel closes the magnetic circuit. All magnets used were $\mathrm{Nd} / \mathrm{Fe} / \mathrm{B}$.

This arrangement readily kept the slurry efficiently stirred even through a 0.25 -in. stainless vessel bottom (which causes some eddy current braking). The system has enough operating margin to restart stirring even after several days of inactivity, which presumably results in complete settling of the slurry at the vessel bottom. A carbon-fiber vessel would probably be preferable, given its lower weight, reduced magnetic field shielding, and partial optical transparency, which would allow observation of the stirrer operation.

As the dry ice warms and liquefies, the container pressure rises and the process continues until the pressure reaches a 
value set by the ambient temperature, as defined by the $\mathrm{CO}_{2}$ phase diagram. At an ambient temperature of $22^{\circ} \mathrm{C}$, the pressure in the vessel will reach about 60 bar. Obviously, up in the stratosphere the vessel temperature is not likely to be at $22^{\circ} \mathrm{C}$ and could perhaps reach $-60^{\circ} \mathrm{C}$ if unattended. Below $-56^{\circ} \mathrm{C}$, the $\mathrm{CO}_{2}$ will freeze, leaving no liquid. For use in such tests, the container will have to be heated to maintain a comparable pressure (perhaps at least 20 bar) if the tests that we have performed are to be somewhat representative of what may be expected under stratospheric conditions.

The original plan was to spray the suspension at a pressure of about 60 bar, in a similar fashion to seawater in the MCB process, using the high-pressure two-fluid effervescent nozzle developed for that application (Cooper et al. 2014). It became apparent after a few trials that the second fluid (compressed air) was not necessary, and hence it was dispensed with to simplify the process. Accordingly, just spraying the liquid from the pressure reservoir through the central feed line of the two-fluid nozzle seemed to do the job, and a series of experiments was performed that way. See section $4 \mathrm{a}$ below for a discussion of these experiments. On a few occasions, however, because the nozzle orifice was small $(200 \mu \mathrm{m})$, it seemed to clog (dry ice will form in the nozzle as the pressure decreases). To this end, eventually the nozzle was removed altogether and just the valve outlet aperture operated as the nozzle. See section $4 \mathrm{~b}$ below for a discussion of these experiments. No plugging was observed during many operations.

Low-power DC electric valves, comprising a simple springloaded plunger activated by a solenoid coil, are both simple and reliable. Since 1000-psig valves are not stock items and required an exceptionally long lead time, we elected to use a 500-psig valve, available off the shelf. We used a KIP 14111 valve with a 3/64-in. $(1.19 \mathrm{~mm})$ orifice in our experiments (high$C_{v}$ valves are recommended for fast flow).

This valve selection required cooling the vessel to $0^{\circ} \mathrm{C}$ in an ice bath to drop the inside pressure to about 35 bar (508 psig), which is within the nominal operating range of the valve. Observations were made at 35 bar as the operating pressure for the dispersal using the outlet of the solenoid valve as a nozzle. As the vessel will reach room temperature and hence higher pressure when stored in our laboratory without cooling, a manual high-pressure valve was added upstream of the electrical valve (see Fig. 9).

The liquid mixture was dispersed in short pulses, typically $0.2-0.3 \mathrm{~s}$ long, directly into the laboratory environment, which was again stirred by two fans, similar to what was done in our previous experiments. As discussed in appendix B, upon spraying, the mixture splits into ultracold dry ice, gas, and carbonate powder. At room temperature the vapor pressure of $\mathrm{CO}_{2}$ is so high and the sublimation of solid $\mathrm{CO}_{2}$ is so fast that dry ice is never observed with the naked eye.

\section{a. Measurement of the particle mass distribution of the aerosol obtained by spraying an ambient-temperature suspension of Albafil $\mathrm{T10}$ in liquid $\mathrm{CO}_{2}$ through a 200- $\mu m$ nozzle}

Figure 10 shows the particle mass distribution obtained using the POPS and SMPS for an aerosol created by spraying an ambient temperature suspension of Albafil T10 in liquid $\mathrm{CO}_{2}$ at 60 bar through a $200-\mu \mathrm{m}$ nozzle.
The POPS data shown in Fig. 10a indicate a mass mode diameter of $1.1 \mu \mathrm{m}$ and a slight broadening of the curve above about $1 \mu \mathrm{m}$. As described in appendix B, in this spray process the expansion of the liquid $\mathrm{CO}_{2}$ gives rise to the formation of ultracold solid $\mathrm{CO}_{2}$. It is possible that the carbonate particles will act as nuclei for the $\mathrm{CO}_{2}$ solids that are formed and thus be significantly cooled by them. While the $\mathrm{CO}_{2}$ should sublime rapidly, the cooled particles might in turn condense ambient moisture, which takes much longer to evaporate, increasing their apparent diameter as measured by the POPS. The SMPS data shown in Fig. 10b are not very different from the SMPS data observed when using dry spraying (Fig. 8b). Again, the data above $450 \mathrm{~nm}$ are larger than they should be, as multiple charge corrections cannot be applied. The trend of the data shows a suggestion of a mass distribution maximum in the submicrometer range, in somewhat noisy data.

\section{b. Measurement of the particle mass distribution of the aerosol obtained by spraying an ice-bath-cooled suspension of Albafil $\mathrm{T10}$ in liquid $\mathrm{CO}_{2}$ at 35 bar directly from the outlet of a solenoid valve}

The data obtained using the simplified arrangement where the solenoid valve outlet acts as the spray nozzle show mostly similar results. Again, measurements were taken simultaneously with the POPS and SMPS.

Figure 11 shows the particle mass distribution of an aerosol created by spraying an ice-bath-cooled suspension of Albafil T10 in liquid $\mathrm{CO}_{2}$ at 35 bar through a $1.19-\mathrm{mm}$ solenoid valve outlet as determined by POPS (Fig. 11a) and SMPS (Fig. 11b).

Once again, the SMPS data shown in Fig. 11b are not very different from the SMPS data observed when using dry spraying (Fig. 8b), with no suggestion of a mass distribution maximum in the submicrometer range. The POPS data shown in Fig. 11a agree very well with the POPS data observed when using dry spraying (Fig. 8a). A mass mode diameter of $1.25 \mu \mathrm{m}$ was observed.

At this point we acquired a TSI model 3321 Aerodynamic Particle Sizer. The instrument, which measures the aerodynamic particle diameter $D_{a}$, collects data over a more extended particle range at the high end. To get true volumetric diameters $D_{v}$, the aerodynamic diameter $D_{a}$ is converted using the formula from Hines (1999), as used by TSI: $D_{v}=D_{a}\left[C_{\mathrm{ae}} \chi /\left(\rho_{p} C_{\mathrm{ve}}\right)\right]^{0.5}$, where $\chi$ is the aerodynamic shape factor $(1.05$, assuming the particles are rounded cubes), $C_{\mathrm{ae}}$ and $C_{\mathrm{ve}}$ are the Cunningham slip factors for the aerodynamic and volumetric particle diameters, and $\rho_{p}$ is the density of the carbonate particles $\left(2.71 \mathrm{~g} \mathrm{~cm}^{-3}\right)$. After conversion, it is found that the instrument limits of the volumetric diameterscale range from 0.35 to $13.7 \mu \mathrm{m}$ (with a well-known decreased detection sensitivity at the lower end of the measuring range).

Aerosol aerodynamic diameter data collected at the same time as the POPS and SMPS data are shown in Figs. 11 and 12. The APS data show a mass mode diameter of $0.87 \mu \mathrm{m}$ and an absence of significant peaks above $1.0 \mu \mathrm{m}$, confirming both the complete separation of individual particles and the absence of agglomerated particles.

\section{Conclusions}

Two simple methods for the dispersal of calcium carbonate at laboratory scale have been described. While these simple 

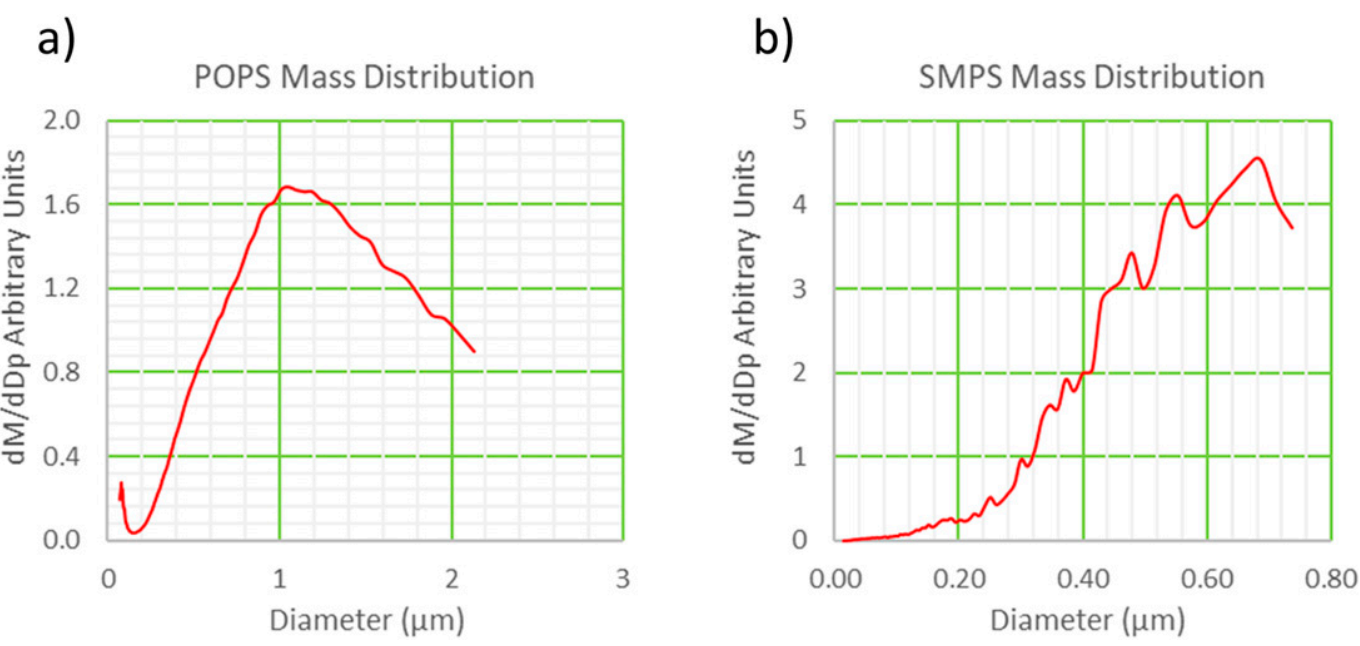

FIG. 10. The particle mass distribution of an aerosol created by spraying an ambient temperature suspension of Albafil T10 in liquid $\mathrm{CO}_{2}$ at 60 bar through a $200-\mu \mathrm{m}$ nozzle as determined by (a) POPS, showing a mass mode diameter of $1.1 \mu \mathrm{m}$, and (b) SMPS, showing a suggestion of a submicrometer peak.

laboratory tests are not sufficiently comprehensive to be considered a feasibility proof for the spraying at the scale that might eventually be required, the apparent ease with which separation of individual submicrometer particles can be obtained is encouraging.

The measured aerosol particle size distributions, using several different standard instruments, are in good agreement with the particle distribution obtained using a flow cytometer. This confirms that complete particle separation is achieved. However, the mass mode diameters measured here (0.87$1.4 \mu \mathrm{m})$ differ from that stated by the manufacturer $(0.7 \mu \mathrm{m})$. A possible explanation for the discrepancy is that each of the instruments used for determining particle size uses a different physical technique, each with its sensitivities to variables. The
SediGraph method measures absorption of an X-ray beam as a function of the sedimentation of particles in a fluid and is sensitive to the density of the particle and the density and viscosity of the fluid. The flow cytometer measures scattering of laser light by particles in an aqueous medium, and is sensitive to particle shape, and refractive index of both the particle and the medium. The POPS measures the scattering of laser light in air and is sensitive to particle shape and refractive index. The SMPS measures charge mobility and is sensitive to particle shape. The APS measures the aerodynamic diameter of particles and is sensitive to particle shape and especially to particle density. Under these circumstances, that the size measurements from all of the instruments used by us agree as well as they do is reassuring.

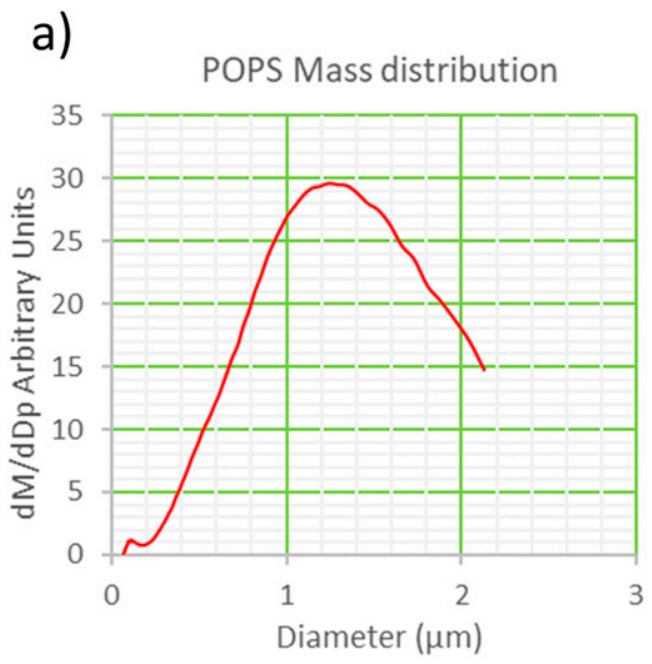

b)

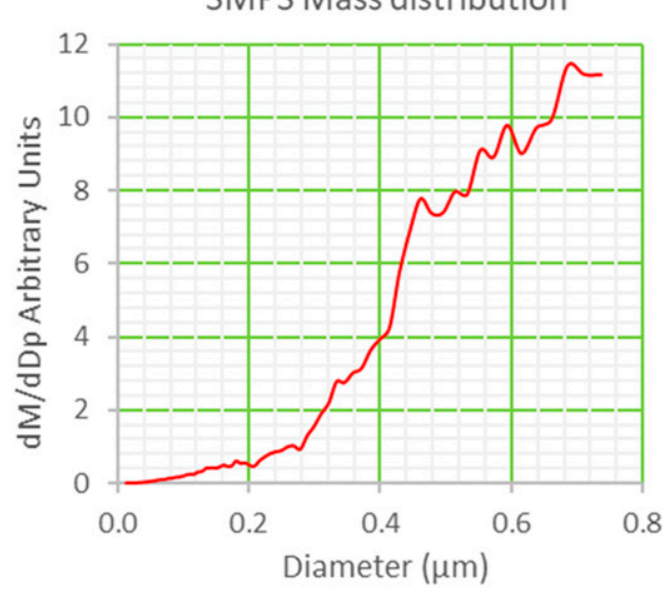

FIG. 11. The particle mass distribution of an aerosol created by spraying an ice-bath-cooled suspension of Albafil T10 in liquid $\mathrm{CO}_{2}$ at 35 bar through a 1.19-mm solenoid valve outlet, as determined by (a) POPS, showing a mass mode diameter of $1.25 \mu \mathrm{m}$, and (b) SMPS, showing no evidence of a submicrometer peak. 


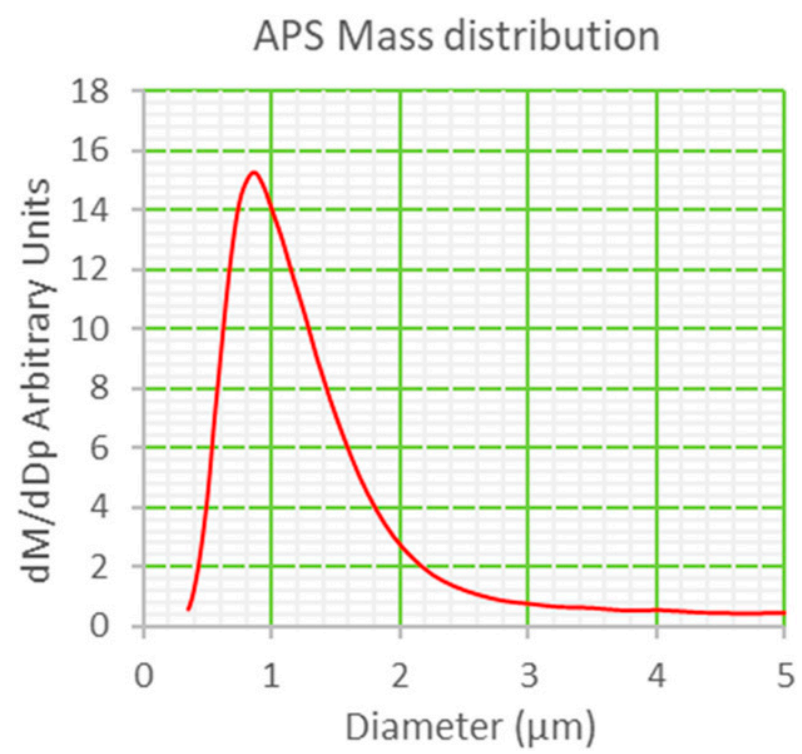

FIG. 12. The particle mass distribution of an aerosol created by spraying an ice-bath-cooled suspension of Albafil T10 in liquid $\mathrm{CO}_{2}$ at 35 bar through a $1.19-\mathrm{mm}$ solenoid valve outlet, as determined by APS, showing a mass mode diameter of $0.87 \mu \mathrm{m}$ and the absence of significant peaks above $1 \mu \mathrm{m}$.

Whereas the spraying of fluidized PCC requires the use of a compressed-air powered two-fluid nozzle to achieve particle separation, the spraying of liquid $\mathrm{CO}_{2}$ suspensions of PCC can be accomplished by release through a simple orifice because suspension in liquid $\mathrm{CO}_{2}$ accomplishes particle separation before spraying.

Acknowledgments. We thank Specialty Minerals, Inc., 260 Columbia St., Adams, Massachusetts 01220, for a sample of Albafil T10; Dr. Yong Chen at Beckman Coulter Life Sciences for CytoFLEX flow cytometry measurements; the Keith and Keutsch groups, and especially Yomay Shyur, at Harvard for their encouragement and for the loan of the POPS instrument; and Sarah Doherty of the Cooperative Institute for Climate, Ocean and Ecosystem Studies for helpful editorial comments. The technical assistance of Bob Ormond is gratefully acknowledged. This work was self-funded. The authors have no conflicts of interest.

Data availability statement. No datasets were generated or analyzed during the current study.

\section{APPENDIX A}

\section{POPS Calibration Using Monodisperse Calcium Carbonate Particles}

Given the importance of the POPS as a possible monitoring instrument for carbonate dispersal in the upper atmosphere, it was decided to calibrate the POPS directly with carbonate particles of known diameter. To this end the DMA of the SMPS was used to select particles of known diameter which

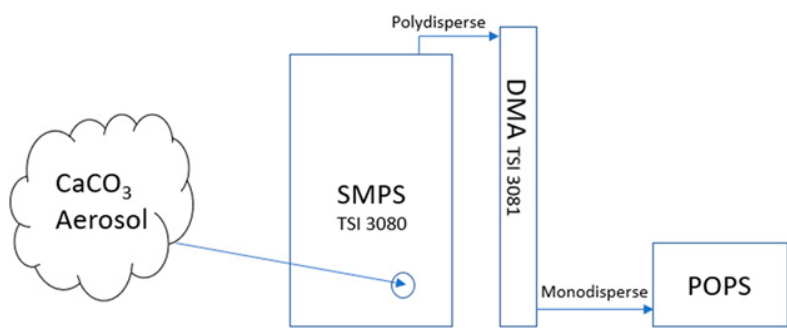

FIG. A1. Use of the SMPS to calibrate the POPS with monodisperse $\mathrm{CaCO}_{3}$ particles.

were then sent to the POPS for measurement. The measurement setup was as illustrated in Fig. A1. The POPS is designed to work at low pressure in the upper atmosphere, and hence can be readily installed as illustrated. Particles of a given diameter (more correctly, mobility) are selected by the voltage setting of the SMPS drift tube and are sent to the POPS for measurement.

The SMPS is limited in principle to a maximum particle size of about $700 \mathrm{~nm}$, but at a given voltage its particle mobility filter simultaneously also selects alias particles of larger size but with equal mobility that can then be measured to extend the range by a factor of 3-4. Particles charged with either 2 or 3 electrons but having a larger diameter will be selected if they have the same mobility.

The electrical mobility of the particle that is selected is related to the quantity $n \operatorname{Cc}(d) / d$, where $n$ is the number of electrons on the particle $(1,2,3,4$, etc.), $d$ is the particle diameter, and $\operatorname{Cc}(d)$ is the Cunningham slip factor. Given the selected primary diameter $d_{p}$ of the one electron particle (and its known slip factor), the diameter of the satellite particles $d_{s}$ can be readily found by solving $\operatorname{Cc}\left(d_{s}\right) / d_{s}=\operatorname{Cc}\left(d_{p}\right) / n d_{p}$ where $n$ is $2,3,4$, and so on.

The result of the 700-nm carbonate particle measurement with the POPS is illustrated in Fig. A2, which shows both the raw data from the POPS (counts vs light intensity) and the normalized bin data. The appearance of the alias satellite particles is clearly evident.

The number of light-intensity bins used by the POPS (which is selectable) was set to $85 \log$ bins to cover the range of the A/D converter output. Hence the width of each bin is different and count normalization is required to locate peaks with good accuracy.

By deconvoluting the illustrated graphs with lognormal distributions and minimizing the residuals with iterative procedures, three peaks in light intensity can be detected, which correspond to the values of carbonate particles with diameters of $0.7,1.28$, and $1.86 \mu \mathrm{m}$ (i.e., the target and two satellite particles as described above). This procedure was repeated for diameter settings of $200,300,400,500$, and $600 \mathrm{~nm}$ on the DMA of the SMPS to fill out the data on intensity versus carbonate particle diameter to construct a carbonate POPS response curve, which is illustrated in Fig. A3.

The graph represents data coming from two independent analyses, using different peak extraction routines. As can be seen extraction of the higher-order peaks has a decreasing 

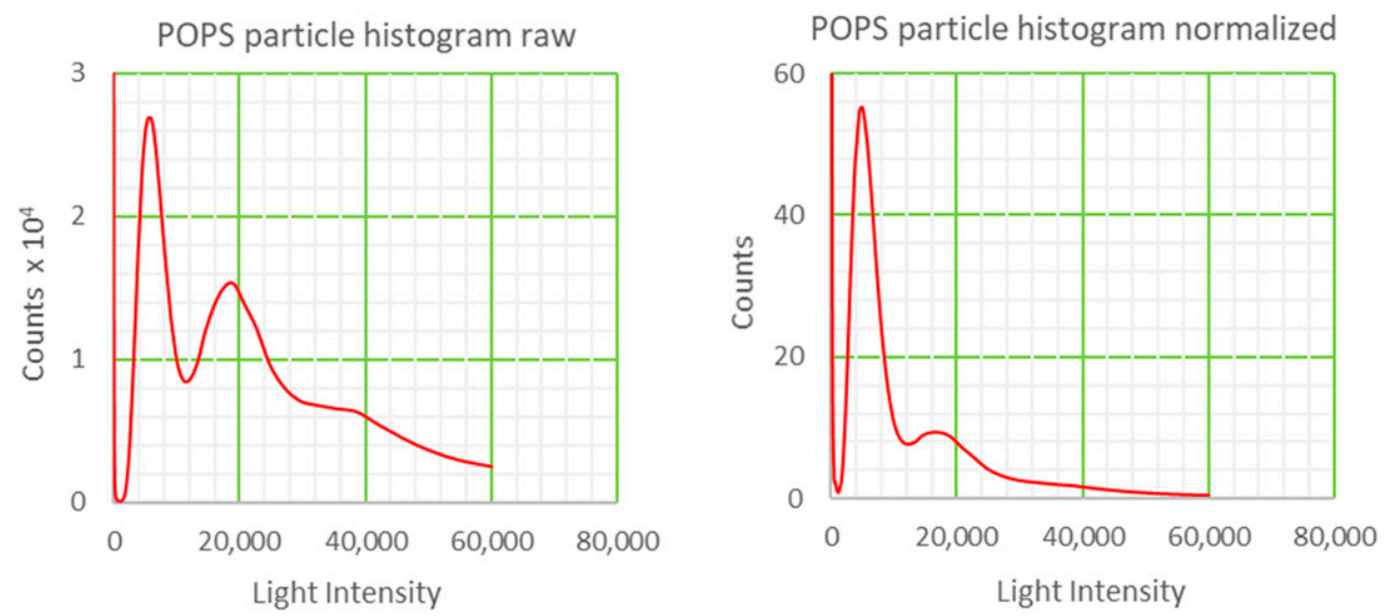

FIG. A2. The POPS particle histogram of a nominal 700-nm calcium carbonate particle selected by the SMPS, in (left) raw and (right) normalized bin form. The primary particle, and two satellite particles resulting from the SMPS selecting single and multiply charged heavier particles, are clearly visible.

accuracy because of compounding errors in peak location. The light-intensity diameter relationship may be approximately represented by the function $I(d)=12900 d^{2.116}$ and, hence conversely, the diameter $d$ can be expressed as $d=$ $(I / 12900)^{1 / 2.116}$. This relationship is valid over most of the range, but there is a hint of a steeper power law when approaching the $0.2-\mu \mathrm{m}$ data region (as would be expected from Rayleigh scattering).

This relationship may be used to take data on POPS counts versus bin light intensity and scale it back into counts versus diameter bins. When the counts are normalized to the variable diameter bin widths, one obtains true continuous distributions. The number of light-intensity bins used by the POPS (a feature that is user selectable) was for historical reasons set to 85 geometrically scaled bin widths to cover the range of the A/D converter output. Hence the width of each bin is different, and count normalization is required to locate peaks with good accuracy.

\section{APPENDIX B}

\section{Thermodynamics of $\mathrm{CO}_{2}$ Expansion}

It can be shown that irreversible free expansion through an orifice to a lower pressure environment does not change the enthalpy of a fluid as long as no heat is exchanged with the surroundings, no mechanical work is done by or on the fluid, and kinetic energy gain is negligible. Suppose we start with liquid in a delivery tank. The liquid is initially on the saturation line at a particular temperature and pressure and has a particular value of enthalpy. If it is then expanded to lower pressure through an orifice, it can no longer be on the saturation line at the starting temperature and pressure since the pressure is much lower (and temperature also drops for reasons that will become clear shortly). However, total enthalpy remains at the starting value. The resolution of this paradox is that the fluid splits into two phases at a new point on the saturation line, with the two phases in thermal equilibrium with each other and therefore at the same (new) temperature, and pressure matching that of the environment being expanded into. Since pressure on the saturation line rises monotonically with temperature, lowering the pressure is tantamount to lowering the temperature. The two phases generally have strongly disparate enthalpies, with the condensed phase having enthalpy lower than the starting value and the vapor having much higher enthalpy. The proportions of the two phases adjust so that the total enthalpy remains at the starting value.

As an illustration, let us start with liquid $\mathrm{CO}_{2}$ at $0^{\circ} \mathrm{C}$ and an absolute pressure of 34.8 bar (on the $\mathrm{CO}_{2}$ saturation line).

\section{POPS Calibration using Calcium Carbonate Particles}

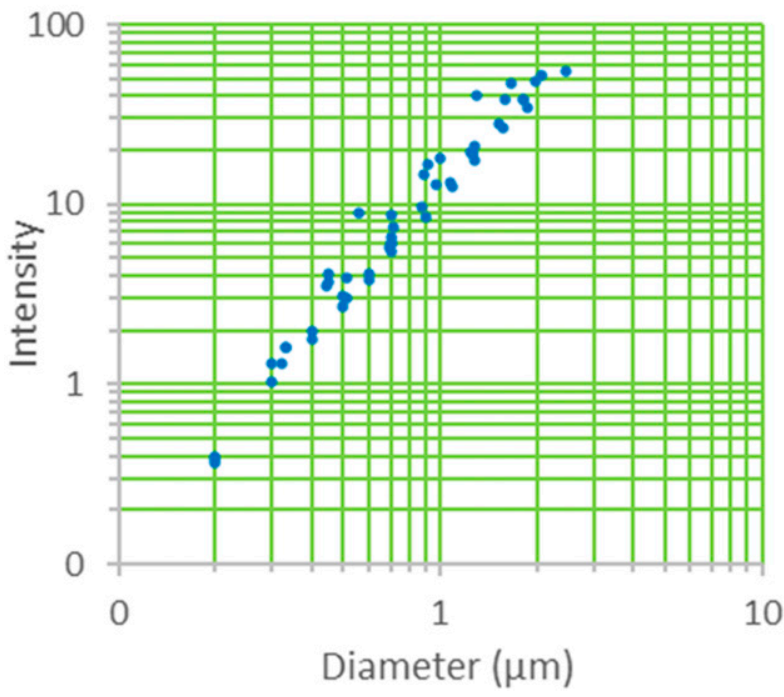

FIG. A3. POPS calibration curve created using monodisperse $\mathrm{CaCO}_{3}$ particles, showing the relationship between light intensity and particle diameter. 
The liquid specific enthalpy is $85.23 \mathrm{~kJ} \mathrm{~kg}^{-1}$. If we expand to an ambient pressure of $220 \mathrm{hPa}$ (mbar, or $\mathrm{mb}$ ) in the stratosphere, for example (about 1/5 of sea level pressure), the liquid splits into vapor and a condensed phase at a new point on the saturation line, and since the vapor pressure of the condensed phase must match the ambient pressure of $220 \mathrm{hPa}$, that can only happen at $-95.6^{\circ} \mathrm{C}$. That temperature will therefore be the temperature of the expanded mixture, which will be vapor and solid since the condensed phase of $\mathrm{CO}_{2}$ is solid below $-56.6^{\circ} \mathrm{C}$.

What are the relative proportions of the two phases? Let the mass fraction of condensed phase be $X$. Then the enthalpy of the condensed phase will be $X H_{\mathrm{cp}}$, and the enthalpy of the vapor phase will be $(1-X) H_{v}$, where $H_{\mathrm{cp}}=$ specific enthalpy of the condensed phase and $H_{v}=$ specific enthalpy of vapor at the same temperature and pressure. The sum of these two enthalpies must equal the starting specific enthalpy of $85.23 \mathrm{~kJ} \mathrm{~kg}^{-1}$. At $220 \mathrm{hPa}$ and $-95.6^{\circ} \mathrm{C}, H_{\mathrm{cp}}=-282.5 \mathrm{~kJ} \mathrm{~kg}^{-1}$ and $H_{v}=300.4 \mathrm{~kJ} \mathrm{~kg}^{-1}$. Solving for $X$ gives 0.369 . So about $37 \%$ of the spray will be solid and the other $63 \%$ will be gaseous $\mathrm{CO}_{2}$. If we start at $20^{\circ} \mathrm{C}$, the starting enthalpy will be $144.3 \mathrm{~kJ} \mathrm{~kg}^{-1}$, and $X=0.268$. So, in addition to a higher starting pressure (57 bar), the fraction of gas after expansion improves to $73 \%$. Interestingly, even if we warm the $\mathrm{CO}_{2}$ to the critical point at $31^{\circ} \mathrm{C}$ and nearly 74 bar, the solid fraction on expansion to $220 \mathrm{hPa}$ is $13 \%(X=0.128)$; there is still some solid $\mathrm{CO}_{2}$ generated.

\section{REFERENCES}

Blackstock, J. J., and Coauthors, 2009: Climate engineering responses to climate emergencies. Novim Group Rep., 56 pp., http://arxiv.org/pdf/0907.5140.

Carr, F. P., and D. K. Frederick, 2000: Calcium carbonate. KirkOthmer Encyclopedia of Chemical Technology, John Wiley and Sons, https://doi.org/10.1002/0471238961.0301120303011818.a01.

Cooper, G., J. Foster, L. Galbraith, S. Jain, A. Neukermans, and B. Ormond, 2014: Preliminary results for salt aerosol production intended for marine cloud brightening, using effervescent spray atomization. Philos. Trans. Roy. Soc. London, 372A, 20140055, https://doi.org/10.1098/ rsta.2014.0055.

Crutzen, P. J., 2006: Albedo enhancement by stratospheric sulfur injections: A contribution to resolve a policy dilemma? Climatic Change, 77, 211-220, https://doi.org/10.1007/s10584006-9101-y.

Dai, Z., D. K. Weisenstein, F. N. Keutsch, and D. W. Keith, 2020: Experimental reaction rates constrain estimates of ozone response to calcium carbonate geoengineering. Commun. Earth Environ., 1, 63, https://doi.org/10.1038/ s43247-020-00058-7.

Dykema, J. A., D. W. Keith, and F. N. Keutsch, 2016: Improved aerosol radiative properties as a foundation for solar geoengineering risk assessment. Geophys. Res. Lett., 43, 7758-7766, https://doi.org/10.1002/2016GL069258.

Ferraro, A. J., A. J. Charlton-Perez, and E. J. Highwood, 2015: Stratospheric dynamics and midlatitude jets under geoengineering with space mirrors and sulfate and titania aerosols. J. Geophys. Res. Atmos., 120, 414-429, https:// doi.org/10.1002/2014JD022734.
Gao, R. S., and Coauthors, 2016: A light-weight, high-sensitivity particle spectrometer for PM2.5 aerosol measurements. Aerosol Sci. Technol., 50, 88-99, https://doi.org/10.1080/ 02786826.2015.1131809.

Geldart, D., 1973: Types of gas fluidization. Powder Technol., 7, 286-292, https://doi.org/10.1016/0032-5910(73)80037-3.

Hines, W., 1999: Aerosol Technology: Properties, Behavior and Measurement of Airborne Particles. 2nd ed. John Wiley and Sons, $504 \mathrm{pp}$.

Keith, D. W., and D. G. MacMartin, 2015: A temporary, moderate and responsive scenario for solar geoengineering. Nat. Climate Change, 5, 201-206, https://doi.org/10.1038/ nclimate2493.

—, D. K. Weisenstein, J. A. Dykema, and F. N. Keutsch, 2016: Stratospheric solar geoengineering without ozone loss. Proc. Natl. Acad. Sci. USA, 113, 14910-14914, https://doi.org/ 10.1073/pnas.1615572113.

Kondo, K., M. Shimmura, and T. Tabuchi, 2013: Measurement of particles in liquid materials using the light scattering method. Rion Co. Tech. Doc., 9 pp., https://www.rion.co.jp/english/ product/docs/p_tech03.pdf.

Kravitz, B., and Coauthors, 2014: A multi-model assessment of regional climate disparities caused by solar geoengineering. Environ. Res. Lett., 9, 074013, https://doi.org/10.1088/17489326/9/7/074013.

National Academies of Sciences, Engineering, and Medicine, 2021: Reflecting Sunlight: Recommendations for Solar Geoengineering Research and Research Governance. National Academies Press, 328 pp., https://doi.org/10.17226/25762.

National Research Council, 2015: Climate Intervention: Reflecting Sunlight to Cool Earth. National Academies Press, 260 pp., https://doi.org/10.17226/18988.

Pope, F. D., P. Braesicke, R. G. Grainger, M. Kalberer, I. M. Watson, P. J. Davidson, and R. A. Cox, 2012: Stratospheric aerosol particles and solar-radiation management. Nat. Climate Change, 2, 713-719, https://doi.org/10.1038/ nclimate 1528.

Prenni, A. J., R. L. Siefert, T. B. Onasch, M. A. Tolbert, and P. J. Demott, 2000: Design and characterization of a fluidized bed aerosol generator: A source for dry, submicrometer aerosol. Aerosol Sci. Technol., 32, 465-481, https://doi.org/10.1080/ 027868200303588 .

Rasch, P. J., S. Tilmes, R. P. Turco, A. Robock, L. Oman, C.-C. (J.) Chen, G. L. Stenchikov, and R. L. Garcia, 2008: An overview of geoengineering of climate using stratospheric sulphate aerosols. Philos. Trans. Roy. Soc. London, 366A, 4007-4037, https://doi.org/10.1098/rsta.2008.0131.

Robock, A., 2000: Volcanic eruptions and climate. Rev. Geophys., 38, 191-219, https://doi.org/10.1029/1998RG000054.

Robrecht, S., B. Vogel, S. Tilmes, and R. Müller, 2021: Potential of future stratospheric ozone loss in the midlatitudes under global warming and sulfate geoengineering. Atmos. Chem. Phys., 21, 2427-2455, https://doi.org/10.5194/acp-21-24272021.

Rogelj, J., and Coauthors, 2018: Mitigation pathways compatible with $1.5^{\circ} \mathrm{C}$ in the context of sustainable development. Global Warming of $1.5^{\circ} \mathrm{C}$, IPCC, 93-174, https:// www.ipcc.ch/site/assets/uploads/sites/2/2019/06/SR15_Full_ Report_Low_Res.pdf.

Shepherd, J., 2009: Geoengineering the climate: Science, governance and uncertainty. Royal Society Rep., 98 pp., https:// royalsociety.org/ /media/Royal_Society_Content/policy/ publications/2009/8693.pdf. 
Silverman, L., and C. E. Billings, 1956: Methods of generating solid aerosols. J. Air Pollut. Control Assoc., 6, 7683, https://doi.org/ 10.1080/00966665.1956.10467737.

Smith, J. P., J. Dykema, and D. Keith, 2018: Production of sulfates onboard an aircraft: Implications for the cost and feasibility of stratospheric solar geoengineering. Earth Space Sci., 5, 150162, https://doi.org/10.1002/2018EA000370.

Smith, W., and G. Wagner, 2018: Stratospheric aerosol injection tactics and costs in the first 15 years of deployment. Environ. Res. Lett., 13, 124001, https://doi.org/10.1088/1748-9326/aae98d.

Teller, E., L. Wood, and R. Hyde, 1997: Global warming and ice ages: I. Prospects for physics based modulation of global change.
Lawrence Livermore National Laboratory Rep., 21 pp., https:// www.osti.gov/servlets/purl/611779.

Tilmes, S., J. H. Richter, M. J. Mills, B. Kravitz, D. G. MacMartin, F. Vitt, J. J. Tribbia, and J.-F. Lamarque, 2017: Sensitivity of aerosol distribution and climate response to stratospheric $\mathrm{SO}_{2}$ injection locations. J. Geophys. Res. Atmos., 122, 12 591-12 615, https://doi.org/10.1002/ 2017JD026888.

Weisenstein, D. K., D. W. Keith, and J. A. Dykema, 2015: Solar geoengineering using solid aerosol in the stratosphere. Atmos. Chem. Phys., 15, 11 835-11 859, https://doi.org/10.5194/acp-1511835-2015. 